\title{
How Does Self-Tracking Go? A Research Model and Pre-Test
}

\author{
Ruth Baumgart \\ Goethe University Frankfurt \\ rbaumgart@wiwi.uni-frankfurt.de
}

\author{
Roland Holten \\ Goethe University Frankfurt \\ holten@wiwi.uni-frankfurt.de
}

\begin{abstract}
Physical inactivity has become a serious problem in modern societies leading to a multitude of diseases. Insurer try to counteract this problem by supporting the use of self-tracking applications. While the effectiveness of self-tracking applications is widely assumed, scant studies investigate the influence of self-tracking applications and those few studies show different results. We propose a research model and measurements based on the cognitive dissonance theory to explain how and why selftracking influences behavior. This understanding is of critical importance for the design of effective selftracking applications. Specifically, we propose that the usage of step-counter apps leads to a higher awareness of two inconsistent cognitions, which induce cognitive dissonance. Because people strive for consistency, they try to reduce the dissonance through either ignoring the situation, finding new information or behavior change. We tested our measurements with an item-sort-task and found high substantive validity as an indicator for good construct validity.
\end{abstract}

\section{Introduction}

Physical inactivity has become a serious public health problem in modern societies leading to an increase in obesity, cardiovascular diseases, diabetes mellitus and cancer [1]. Insurer and other companies try to counteract this problem through supporting the use of self-tracking application as a health protection intervention [2, 3]. The term self-tracking is hereby defined as the use of technology to gather personal information about e.g. calorie intake, steps or sleeping habits $[4,5]$.

While the importance of information systems in the healthcare domain is highly emphasized [6] and the effectiveness of self-tracking is widely presumed, only a few studies investigate the actual influence of self-tracking and those few studies found contradictory results. Some of these investigations report a desired behavior change [7], but other studies found different responses to self-tracking $[8,9]$.

Hence, the goal of this study is to investigate the influence of self-tracking on behavior, emotion and cognition and to find an explanation for the different responses to self-tracking. This psychological understanding is critically important for designing efficient applications to motivate people to get moving [10]. Our investigation is based on the cognitive dissonance theory, which is one of the grandest theories in social psychology [11] and combines emotion, cognition and motivation. The theory suggests that an inconsistency of attitude and behavior leads to cognitive dissonance, which denotes a psychological tension [12]. Because cognitive dissonance is an unpleasant feeling, people who experience it try to reduce the dissonance by using three different strategies: Changing cognitive elements of the environment by, e.g. ignoring a situation, adding new cognitive elements through finding new information or changing the behavior. These strategies help to bring attitude and behavior in line with each other again.

Cognitive dissonance theory has so far been tested in experiments in which subjects could reduce dissonance in only one predetermined way [13, 14]. A reaction in a way that the cognitive dissonance theory predicted was seen as a support for this theory. Critical voices pointed to built-in artifacts or potential biases because the results could also be explained through other theories [15]. Therefore, we propose a research model and respective measurement scales to test this theory. To the best of our knowledge, the cognitive dissonance theory is to date not fully operationalized. While some investigation have developed a measurement scale for cognitive dissonance [16] and other investigations use the expectation disconfirmation theory as a modification of the cognitive dissonance theory [17], we found no fully tested constructs for the dissonance reduction strategies.

Furthermore, because of calls for more studies as to the nature and consequences of the digital mediation of everyday experience [18], we also 
explore the interrelationship between self-tracking and the cognitive dissonance mechanism.

This leads to the central research questions:

1. What are valid scales for measuring the dissonance reduction strategies in a self-tracking context?

2. How and why does self-tracking interact with emotions, cognition and behavior?

The remainder of this paper is structured as follows. In the next section, the theoretical background and related work is provided. After that, the research model is described and the analysis is presented. The paper finishes with a discussion of the results and a conclusion.

\section{Theoretical Background}

\subsection{Self-tracking}

The Quantified Self movement was started by Gary Wolf and Kevin Kelly in 2007 when sensors became smaller, cheaper and easier to implement in mobile devices [19]. Members of this community engage on social network sites and worldwide in personal meetings to talk about new technologies and self-tracking experiences. Self-tracking is thereby defined as using technology to record and observe personal information for the purpose of selfreflection and self-knowledge. There are different areas for self-tracking services e.g. internal states (as mood or galvanic skin response), performance values (pace or number of steps), habits (as food intake or sleep) and actions (as visited places) [20].

Because walking 10,000 steps has a desired health effect [21], we focus on the performance values in the area of step counter application.

To date, only a few researchers have investigated the effect of self-tracking on physical activity and those few studies report different reactions to selftracking usage. While a meta study by Bravata et al. 2007 shows a significant increase as to the step amount in a clinical context when utilizing mechanical pedometers [7], Sanchez-Valdes and Trivino (2015) show different reactions to selftracking. In a single subject experimental design, they tried to induce moderate physical activity to three different users by providing a self-tracking application with emotional and linguistic feedback. While two participants changed their behavior in a desired way, one participant could not reach the goal of moderate physical activity [8]. Furthermore, Sjöklint (2015) shows different responses to the use of step counter applications [9]. In a qualitative investigation, they found out that people feel more motivated when using self-tracking applications. When the goal was not reached, the participants investigated coping strategies. These coping strategies are disregard, procrastination, selective attention or neglect. Disregard is a strategy in which people formulate excuses to explain why the goal was not reached. Procrastination is the tendency in self-trackers to invest in plans for reaching the goal at a later point in time. Selective attention happens when self-trackers only focus on goals that are easy to reach for them and neglect means that the users do not look at the data until they are sure that they have reached their goal.

Baumgart (2016) suggest that the cognitive dissonance theory is a possible explanation for the different responses and proposed a research model based on interview data [22]. While this is a first indicator that the cognitive dissonance theory is applicable in a self-tracking context, no investigation has developed and fully tested appropriate measurement scales for a quantitative examination as to the influence of self-tracking on behavior, emotions and cognitions. This quantitative examination is important for ensuring greater generalizability.

Therefore, we have developed and tested new measurement scales based on the cognitive dissonance theory to find out how and why selftracking influences behavior, emotions and cognitions.

\subsection{Cognitive dissonance theory}

Cognitive dissonance is defined as a psychological tension, which arises when a person is simultaneously aware of two inconsistent cognitions [12]. For example, dissonance arises when the behavior is not in line with attitude. Because dissonance is an unpleasant feeling, people try to reduce it through three different approaches [12]: Changing an environmental cognitive element, adding new cognitive elements or changing behavioral cognitive elements. Whenever dissonance is reduced through ignoring the situation or changing the attitude, the strategy changing an environmental cognitive element is used. The dissonance reduction strategy adding new cognitive elements is used when a person searches for new information to bring the two inconsistent cognitions in line with each other. Changing behavioral cognitive elements means that dissonance is reduced by modifying the behavior. For example, if the behavior is not in line with personal goals and attitudes, the person can reduce dissonance through changing the behavior. The cognitive 
dissonance theory is sometimes considered as a universal behavior pattern across individuals [23].

In psychological investigations, the dissonance theory has been tested with experiments where the research participants were given only one possibility for reducing dissonance $[13,14]$. A reaction in a way that the theory predicted was taken as a support for the cognitive dissonance theory. This approach was often criticized as biased because other explanations for the same results are possible [15]. In 2000, the first established scale to measure cognitive dissonance was developed in a psychology and marketing context [16]. Four years later, Bhattacherjee and Premkumar (2004) developed the expectation disconfirmation model in an Information Systems context, which is a modification of the cognitive dissonance theory [17]. To the best of our knowledge, no fully tested measurement of the three dissonance reduction strategies exists to date. The goal of this study is therefore the operationalization and testing of the three dissonance reduction strategies as well as the presentation of a research model, which exhibit the interaction between cognitive dissonance and self-tracking.

\section{Research model}

Based on the cognitive dissonance theory and Baumgart (2016), we propose a research model and the respective measurement scales that investigates the interaction of self-tracking with cognition, emotion and behavior. In sum, we posit that increased use of self-tracking leads to more dissonance and in consequence to the three reduction strategies. Figure 1 summarizes the model.

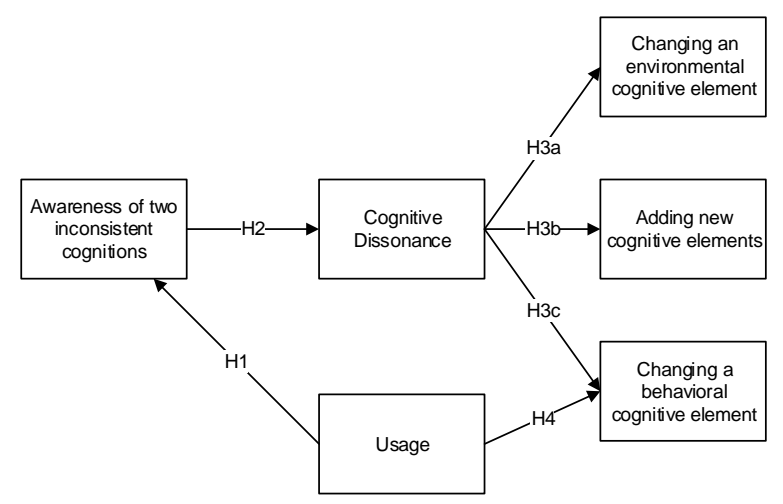

Figure 1. Research model

We derive the following hypothesis. In accordance with Baumgart (2016), we assume that the use of self-tracking software leads to a greater awareness of two inconsistent cognitions because the software provides information about the step amount, which is otherwise more difficult to obtain.

H1: The higher the use of self-tracking software, the greater the awareness of two inconsistent cognitions.

Furthermore, in line with the cognitive dissonance theory, we assume that the awareness of two inconsistent cognitions leads to psychological discomfort (dissonance) because people strive for cognitive consistency [12].

$\mathrm{H} 2$ : The higher the awareness of two inconsistent cognitions, the higher the dissonance.

Because dissonance is seen as an unpleasant feeling, people try to reduce this dissonance by utilizing different dissonance reduction strategies. One reduction strategy is to ignore or deny the situation [12]. Therefore, we assume that a greater amount of dissonance leads to a higher tendency to ignore the step counter results.

H3a: An increase in dissonance leads to an increase in the dissonance reduction strategy changing an environmental cognitive element.

Another dissonance reduction strategy is to search for new information, which reduces the inconsistency of two cognitions [12]. In the case of step counters, we assume that self-trackers search for new information in order to explain insufficient walking.

H3b: An increase in dissonance leads to an increase in the dissonance reduction strategy adding new cognitive elements.

There is also the possibility of reducing dissonance by changing the behavior to bring behavior and cognition in line with each other [12] . Therefore, we assume that an increase in dissonance leads to a change in behavior.

$\mathrm{H} 3 \mathrm{c}$ : An increase in dissonance leads to the dissonance reduction strategy of changing a behavioral cognitive element.

While self-tracking is a relative new concept, selfmonitoring in the area of behavioral psychology goes back to 1970 [24]. A multitude of research found that increased self-awareness trough self-monitoring facilitates the intended behavior change [25, 26]. Also in the context of self-tracking, a desired behavior change was found in a multitude of settings [7]. We therefore assume that the greater selfawareness through self-tracking leads to a desired behavior change.

H4: The use of self-tracking leads to behavior change.

Trost et al. (2001) found a significant age and gender difference in physical activity [27]. Therefore, we include these variables as control variables to our model. Table 1 summarizes the key constructs. 
Table 1. Construct definition

\begin{tabular}{|l|l|}
\hline Construct & Definition and description \\
\hline $\begin{array}{l}\text { Awareness of two } \\
\text { inconsistent } \\
\text { cognition [12, 17, } \\
22]\end{array}$ & $\begin{array}{l}\text { Awareness of two inconsistent } \\
\text { cognitions refers to the extent to } \\
\text { which two cognitions of a } \\
\text { person, e.g. subject's attitude } \\
\text { and behavior, are inconsistent. }\end{array}$ \\
\hline $\begin{array}{l}\text { Cognitive } \\
\text { dissonance [12, } \\
13,16,28]\end{array}$ & $\begin{array}{l}\text { Cognitive dissonance is defined } \\
\text { as psychological discomfort, } \\
\text { which arises if two cognitions of } \\
\text { a person are inconsistent. }\end{array}$ \\
\hline $\begin{array}{l}\text { Changing an } \\
\text { environmental } \\
\text { cognitive element } \\
{[12]}\end{array}$ & $\begin{array}{l}\text { Changing an environmental } \\
\text { cognitive element refers to the } \\
\text { reduction of dissonance through } \\
\text { ignoring the dissonance- } \\
\text { inducing situation. }\end{array}$ \\
\hline $\begin{array}{l}\text { Adding new } \\
\text { cognitive } \\
\text { elements [12] }\end{array}$ & $\begin{array}{l}\text { Adding new cognitive elements } \\
\text { refers to the reduction of } \\
\text { dissonance through the addition } \\
\text { of new information to bring } \\
\text { behavior and cognition in line. }\end{array}$ \\
\hline $\begin{array}{l}\text { Changing a } \\
\text { behavioral } \\
\text { cognitive element } \\
{[12]}\end{array}$ & $\begin{array}{l}\text { Changing a behavioral cognitive } \\
\text { element refers to the reduction } \\
\text { of dissonance through the } \\
\text { modification of an action. }\end{array}$ \\
\hline Usage [29] & $\begin{array}{l}\text { Usage provides information } \\
\text { about the extent and frequency } \\
\text { of self-tracking usage. }\end{array}$ \\
\hline
\end{tabular}

\section{Measurement scale development}

Next, we developed measurement scales for our construct, which are presented in Table 2.

It is important to have adequately measured variables to identify significant relationships between the constructs [30]. To ensure content validity, we conducted a literature review in order to adopt items from existing questionnaires. To the best of our knowledge, no constructs for the three dissonance reduction strategies have so far been fully tested. Therefore, we developed new items based on established guidelines and the construct definitions [31]. Furthermore, we conducted interviews with 20 self-tracking user, to find appropriate items for the dissonance reduction strategies in a self-tracking context. The interviewees were acquired from sport clubs and from university. The average age was 28.95 (SD = 6.95). To support the development of new items, we ask the interviewees how they react to self-tracking when they have not reached their goal.

Only the construct awareness of two inconsistent cognitions is based on existing and well-tested items [17]. The short-scale cognitive dissonance construct from Elliot and Devine 1994 [13] has not been empirical validated before [16].

In a first step, we evaluated whether the constructs are measured in a formative or reflective scale by following established guidelines [32, 33].

Table 2. Items and constructs

\begin{tabular}{|c|c|c|c|}
\hline Construct & \multicolumn{2}{|l|}{ Item } & Reference \\
\hline & \multicolumn{2}{|c|}{ Last time when I did not walk much... } & \\
\hline \multirow{3}{*}{$\begin{array}{l}\text { Awareness of two } \\
\text { inconsistent } \\
\text { cognition }\end{array}$} & IC1 & ... my step amount was much worse than I had intended. & \multirow{3}{*}{$\begin{array}{l}\text { Adapted } \\
\text { from [17] }\end{array}$} \\
\hline & IC2 & $\begin{array}{l}\text {... my step level, compared to my goal, was much worse than I had } \\
\text { planned. }\end{array}$ & \\
\hline & IC3 & .. I walked less than I intended. & \\
\hline \multirow{3}{*}{$\begin{array}{l}\text { Cognitive } \\
\text { dissonance }\end{array}$} & CD1 & ... I felt uncomfortable. & \multirow{3}{*}{$\begin{array}{l}\text { Adapted } \\
\text { from [13] }\end{array}$} \\
\hline & CD2 & ... I felt uneasy. & \\
\hline & CD3 & .. I felt bothered. & \\
\hline \multirow{4}{*}{$\begin{array}{l}\text { Changing an } \\
\text { environmental } \\
\text { cognitive element }\end{array}$} & EC1 & $\begin{array}{l}\text {.. after that I did not think any longer about how good or bad my } \\
\text { walking performance is. }\end{array}$ & \multirow[t]{4}{*}{$\begin{array}{l}\text { Newly } \\
\text { developed }\end{array}$} \\
\hline & EC2 & $\ldots$ after that I ignored my walking performance. & \\
\hline & EC3 & $\ldots$ after that I did not observe my walking performance any longer. & \\
\hline & EC4 & $\ldots$ after that I payed less attention to my step performance. & \\
\hline \multirow{3}{*}{$\begin{array}{l}\text { Adding new } \\
\text { cognitive elements }\end{array}$} & $\mathrm{NC1}$ & ... I searched for an explanation for this performance. & \multirow{3}{*}{$\begin{array}{l}\text { Newly } \\
\text { developed }\end{array}$} \\
\hline & NC2 & ... I asked myself whether there was a reason for that. & \\
\hline & NC3 & ... I reflected why I had not walked more. & \\
\hline \multirow{3}{*}{$\begin{array}{l}\text { Changing a } \\
\text { behavioral } \\
\text { cognitive element }\end{array}$} & $\mathrm{BC} 1$ & ... my subsequent step performance corresponded to my set target. & \multirow{3}{*}{$\begin{array}{l}\text { Newly } \\
\text { developed }\end{array}$} \\
\hline & $\mathrm{BC} 2$ & ... I subsequently tried to walk more. & \\
\hline & BC3 & ... I went out again to walk more. & \\
\hline \multirow[t]{4}{*}{ Usage } & U1 & How often do you look at your step quantity per day? & \multirow{4}{*}{$\begin{array}{l}\begin{array}{l}\text { Newly } \\
\text { developed }\end{array} \\
\quad \text { Page } 31 \\
\end{array}$} \\
\hline & $\mathrm{U} 2$ & How frequently do you carry a step counter with you? & \\
\hline & $\mathrm{U} 2$ & How do you consider the extent of your current step counter usage? & \\
\hline & $\mathrm{U} 4$ & How many hours per day capture the step counter your steps? & \\
\hline
\end{tabular}


We conclude that every construct is defined in a reflective way because the items are mutually interchangeable and represent consequences of the construct.

\section{Data collection and analysis}

In order to reduce ambiguity and bias in the meaning of the new and reworded reflective items, we conducted a pretest [34, 35]. As a method, we used the item-sort task by Anderson and Gerbing (1991) because this method is suitable for discovering wording-related issues, requires only a small sample size and is widely established in scale development studies [36]. Furthermore, the item-sort task is an appropriate method for assessing substantive validity, which is defined as the extent to which a measure is theoretical linked to the construct of interest [37]. Substantive validity is thereby a necessary prerequisite for the construct validity of newly developed constructs [37].

In order to conduct the items sort task, 19 participants with self-tracking experience or an academic background were recruited. This sample size is seen as appropriate for an item-sort-task [38].

$74 \%$ of the participants were male and $26 \%$ were female. The item-sort-task was conducted in German.

The participants received a set of constructs defined in everyday language [39] and randomly sorted items. Every respondent received written instructions asking them to assign each item to the most suitable construct and check each item again after completing the task. We also encouraged the participants to give feedback on single items and definitions.

For the evaluation of substantive validity, we calculated two indices as proposed by Anderson and Gerbing (1991) [37]. The first index, the proportion of substantive agreement $p s a$, is defined as the proportion of participants assigning an item to the intended construct. In order to determine the extent to which an item also fits another construct, the second index substantive-validity coefficient csv is calculated representing the extent to which respondents assign an item to its posited construct more frequently than to any other construct. The values of $p s a$ range from 0.0 to 1.0 and the values of $c s v$ range from -1.0 to 1.0 with larger values indicating greater substantive validity.

At first, we calculated the critical number of assignments $(\mathrm{m})$ to receive the critical value for $c s v$ by defining a 0.05 level of significance. The critical number of assignments (m) is determined by summing up the binomial probabilities $(0.5$ probability) of a certain number of responses starting with the maximum possible amount and decreasing it until the sum of the probabilities is smaller than 0.05. Since we had 19 respondents, our critical number of assignments is 14 . The corresponding critical value of $c s v$ is 0.473 . Table 3 summarizes the results for the two indices for every single item.

Table 3. Substantive validity results

\begin{tabular}{|c|c|c|c|}
\hline Construct & Item & psa & csv \\
\hline \multirow{3}{*}{$\begin{array}{l}\text { Awareness of two } \\
\text { inconsistent } \\
\text { cognition }\end{array}$} & IC1 & $0.95^{* * *}$ & $0.89 * * *$ \\
\hline & $\begin{array}{l}\text { IC2 } \\
\end{array}$ & $1 * * *$ & $1 * * *$ \\
\hline & IC3 & $1 * * *$ & $1 * * *$ \\
\hline \multirow[t]{3}{*}{ Cognitive dissonance } & CD1 & $0.95^{* * *}$ & $0.89 * * *$ \\
\hline & $\mathrm{CD} 2$ & $1 * * *$ & $1 * * *$ \\
\hline & CD3 & $1 * * *$ & $1 * * *$ \\
\hline \multirow{4}{*}{$\begin{array}{l}\text { Changing an } \\
\text { environmental } \\
\text { cognitive element }\end{array}$} & EC1 & $1 * * *$ & $1 * * *$ \\
\hline & $\mathrm{EC} 2$ & $1 * * *$ & $1 * * *$ \\
\hline & EC3 & $0.95^{* * *}$ & 0.89 *** \\
\hline & EC4 & $0.95^{* * *}$ & 0.89 *** \\
\hline \multirow{3}{*}{$\begin{array}{l}\text { Adding new } \\
\text { cognitive elements }\end{array}$} & $\mathrm{NC1}$ & $0.89 * * *$ & $0.84 * * *$ \\
\hline & $\mathrm{NC2}$ & $0.95^{* * *}$ & 0.89 *** \\
\hline & $\mathrm{NC} 3$ & $0.89^{* * *}$ & $0.84 * * *$ \\
\hline \multirow{3}{*}{$\begin{array}{l}\text { Changing a } \\
\text { behavioral cognitive } \\
\text { element }\end{array}$} & $\mathrm{BC} 1$ & $0.89^{* * *}$ & $0.84 * * *$ \\
\hline & $\mathrm{BC} 2$ & $0.95^{* * *}$ & $0.89 * * *$ \\
\hline & BC3 & $1 * * *$ & $1 * * *$ \\
\hline \multirow[t]{4}{*}{ Usage } & U1 & $1 * * *$ & $1 * * *$ \\
\hline & $\mathrm{U} 2$ & $1 * * *$ & $1 * * *$ \\
\hline & U3 & $1 * * *$ & $1 * * *$ \\
\hline & $\mathrm{U} 4$ & $1 * * *$ & $1 * * *$ \\
\hline
\end{tabular}

Both indices are significant for each item. These results indicate high substantive validity and therefore, good construct validity.

Most of the wrong assignments were made regarding the items of the construct adding new cognitive elements. A few participants linked some of these items to the construct changing a behavioral cognitive element.

However, the probability that the correct assignments were done by chance is less than $1 \%$ for each item. Furthermore, the $c s v$ value of each item does not fall below the critical value of 0.47 . So the results suggest that each item measures the corresponding constructs appropriately. 


\section{Discussion and conclusion}

The aim of this investigation was to build a measurement model that is suitable for our research model, which explains how and why self-tracking influences behavior, emotion and cognition in a stepcounter context. The cognitive dissonance theory was used as a foundation because it is one of the most important theories in social psychology. Our research model states that the usage of step counter apps leads to a higher awareness of two inconsistent cognitions. This awareness triggers cognitive dissonance, which is a psychological tension. To reduce dissonance, people engage in three different dissonance reduction strategies: They ignore the situation, add new information or change their behavior.

The cognitive dissonance theory was mostly tested in experiments in which participants could reduce dissonance in just one predefined way. A reaction as to compliance with the theory was seen as a support of the theory. This indirect approach earned a lot of criticism because other explanations for the obtained results are also possible [15, 23]. Therefore, we built and tested latent constructs as a prerequisite to test the theory with a more direct method.

To ensure content validity, we based our scales on existing measurement scales from prior literature. Because the expectation disconfirmation theory is a modification of the cognitive dissonance theory, we based our construct awareness of two inconsistent cognitions on it. While the construct cognitive dissonance has also been developed, no fully tested operationalization of the three dissonance reduction strategies exist to date. Therefore, we based our items on construct definitions and interviews with selftracking users to develop appropriate items for the operationalization of the dissonance reduction strategies.

Before testing the model, we conducted an itemsort-task with 19 participants. The results show that our newly developed scales measure the respective constructs appropriately. The paper provides the rigorous development of valid measurements scales. The described procedure ensures high levels of confidence in content and substantive validity as a strong indicator for construct validity.

For practice, our research model gives important insights into how and why self-tracking influences behavior and cognition. This psychological understanding is critically important for the design of effective self-tracking apps, which could reduce the usage of unwanted dissonance reduction strategies.

There are several limitations to our investigation. The results of our pre-test are only indications of the reliability and validity of our construct. Without a pilot test and the assessment of the overall questionnaire only initial indications of construct validity are derived. The items were developed for a step counter context. Nevertheless, the scales are also applicable to a wide variety of contexts with slight modifications. Furthermore, it is not possible to draw any conclusions in terms of our hypothesis. We will test the hypothesis in further investigations.

This investigation contributes to the body of knowledge through the development and testing of a measurement scale which explains how and why selftracking influences behavior and cognition on the basis of the cognitive dissonance theory. This wellestablished theory was tested only with experiments. This approach was criticized because of other possible explanations for the discovered results. Because the cognitive dissonance theory has not been fully operationalized, we developed measurements for the three dissonance reduction strategies in a selftracking context. Furthermore, we tested the items with an item-sort-task and found support for the substantive validity, which is an indicator of construct validity.

\section{References}

[1] Who, "Physical Activity", http://www.who.int/mediacentre/factsheets/fs385/en/, accessed 28.02.2017.

[2] Aok, "AOK Leistungen", http://www.aok.de/nordost/leistungen-service/aokgesundheitskonto-248715.php\#248725, accessed 27.11.2015.

[3] F. Nikayin, M. Heikkilä, M. De Reuver, and S. Solaimani, "Workplace Primary Prevention Programmes Enabled by Information and Communication Technology", Technological Forecasting and Social Change, 89, 2014, pp. 326-332.

[4] I. Li, A.K. Dey, and J. Forlizzi, "A Stage-Based Model of Personal Informatics Systems", Proceedings of the Conference on Computer-Human Interaction, 2010.

[5] E.K. Choe, N.B. Lee, B. Lee, W. Pratt and J. A. Kientz, "Understanding Quantified-Selfers' Practices in Collecting and Exploring Personal Data", in: Proceedings of the 32nd Annual ACM Conference on Human Factors in Computing Systems, ACM, 2014, pp. 1143-1152.

[6] R.G. Fichman, R. Kohli, and R. Krishnan, "Editorial Overview-the Role of Information Systems in Healthcare: Current Research and Future Trends", Information Systems Research, 22(3), 2011, pp. 419-428.

[7] D.M. Bravata, C. Smith-Spangler, V. Sundaram, A. L. Gienger, N. Lin, R. Lewis, C. D. Stave, O. Ingram, and J. 
R. Sirard, "Using Pedometers to Increase Physical Activity and Improve Health: a Systematic Review", JAMA, 298(19), 2007, pp. 2296-2304.

[8] D. Sanchez-Valdes, and G. Trivino, "Linguistic and Emotional Feedback for Self-Tracking Physical Activity", Expert Systems with Applications, 42(24), 2015, pp. 9574 9586.

[9] M. Sjöklint, I.D. Constantiou, and M. Trier, "The Complexities of Self-Tracking - an Inquiry into User Reactions and Goal Attainment", Münster, 2015.

[10] S. Wendel, Designing for behavior change: Applying Psychology and Behavioral Economics, " O'Reilly Media, Inc.", Sebastopol, CA, 2013.

[11] E. Aronson, "The Return of the Repressed: Dissonance Theory Makes a Comeback", Psychological Inquiry, 3(4), 1992, pp. 303-311.

[12] L. Festinger, A Theory of Cognitive Dissonance, Stanford University Press, Stanford, California, 1962.

[13] A.J. Elliot, and P.G. Devine, "On the Motivational Nature of Cognitive Dissonance: Dissonance as Psychological Discomfort", Journal of Personality and Social Psychology, 67(3), 1994, pp. 382-394.

[14] M.B. Menasco, and D.I. Hawkins, "A Field Test of the Relationship between Cognitive Dissonance and State Anxiety", Journal of Marketing Research, 1978, pp. 650655 .

[15] S. Oshikawa, "Can Cognitive Dissonance Theory Explain Consumer Behavior?", The Journal of Marketing, 1969, pp. 44-49.

[16] J.C. Sweeney, D. Hausknecht, and G.N. Soutar, "Cognitive Dissonance after Purchase: a Multidimensional Scale", Psychology and Marketing, 17(5), 2000, pp. 369385.

[17] A. Bhattacherjee, and G. Premkumar, "Understanding Changes in Belief and Attitude toward Information Technology Usage: a Theoretical Model and Longitudinal Test", MIS Quarterly, 2004, pp. 229-254.

[18] Y. Yoo, "Computing in Everyday Life: a Call for Research on Experiential Computing", MIS Quarterly, 2010, pp. 213-231.

[19] H. Gimpel, M. Nißen, and R. Görlitz, "Quantifying the Quantified Self: a Study on the Motivations of Patients to Track their own Health", in: Thirty Fourth International Conference on Information Systems (ICIS 2013), Milan, 2013.

[20] A. Rapp, and F. Cena, "Self-Monitoring and Technology: Challenges and Open Issues in Personal Informatics", in: International Conference on Universal
Access in Human-Computer Interaction, Springer, 2014, pp. 613-622.

[21] C. Tudor-Locke, B. Ainsworth, M. Whitt, et al., "The Relationship between Pedometer-Determined Ambulatory Activity and Body Composition Variables", International Journal of Obesity, 25(11), 2001, pp. 1571-1578.

[22] R. Baumgart, "How Does Quantified Self Run?", Proceedings of the 22nd Americas Conference on Information Systems (AMCIS 2016), San Diego, California, USA, 2016

[23] J. Cooper, Cognitive Dissonance: 50 Years of a Classic theory, Sage Publications Ltd, London, 2007.

[24] J. Kopp, "Self-monitoring: A Literature Review of Research and Practice", in: Social Work Research and Abstracts, Oxford University Press, 1988, pp. 8-20.

[25] L.E. Burke, M.A. Styn, K. Glanz, L. J. Ewing, O. U. Elci, M. B. Conroy, S. M. Sereika, S. D. Acharya, E. Music, A. L. Keating and M. A. Sevick., "SMART trial: a Randomized Clinical Trial of Self-Monitoring in Behavioral Weight Management-Design and Baseline Findings", Contemporary Clinical Trials, 30(6), 2009, pp. 540-551.

[26] M.H. Wilde, and S. Garvin, "A Concept Analysis of Self-Monitoring", Journal of Advanced Nursing, 57(3), 2007, pp. 339-350.

[27] S.G. Trost, R.R. Pate, J.F. Sallis, P. S. Freedson, W. C. Taylor, M. Dowda, and J. Sirard, "Age and Gender Differences in Objectively Measured Physical Activity in Youth", Medicine and Science in Sports and Exercise, 34(2), 2002, pp. 350-355.

[28] J.M. Carlsmith, and E. Aronson, "Some Hedonic Consequences of the Confirmation and Disconfirmation of Expectances", The Journal of Abnormal and Social Psychology, 66(2), 1963, pp. 151-156.

[29] F.D. Davis, "Perceived Usefulness, Perceived Ease of Use, and User Acceptance of Information Technology", MIS Quarterly, 1989, pp. 319-340.

[30] S.W. O'leary-Kelly, and R.J. Vokurka, "The Empirical Assessment of Construct Validity", Journal of Operations Management, 16(4), 1998, pp. 387-405.

[31] G.C. Moore, and I. Benbasat, "Development of an Instrument to Measure the Perceptions of Adopting an Information Technology Innovation", Information Systems Research, 2(3), 1991, pp. 192-222.

[32] J.R. Rossiter, "The C-OAR-SE Procedure for Scale Development in Marketing", International Journal of Research in Marketing, 19(4), 2002, pp. 305-335. 
[33] W.W. Chin, "The Partial Least Squares Approach to Structural Equation Modeling", Modern Methods for Business Research, 295(2), 1998, pp. 295-336.

[34] G.A. Churchill, Jr., Marketing Research, Dryden Press Chicago, 4th ed., 1987.

[35] P.E. Green, D.S. Tull, and G. Albaumg, Research for Marketing Decisions, Englewood Cliffs, 5th ed., NJ: Prentice-Hall, 1988.

[36] M.C. Howard, and R.C. Melloy, "Evaluating Item-Sort Task Methods: The Presentation of a New Statistical Significance Formula and Methodological Best Practices", Journal of Business and Psychology, 31(1), 2016, pp. 173186.

[37] J.C. Anderson, and D.W. Gerbing, "Predicting the Performance of Measures in a Confirmatory Factor Analysis with a Pretest Assessment of their Substantive Validities", Journal of Applied Psychology, 76(5), 1991, pp. 732-740.

[38] S.D. Hunt, R.D. Sparkman Jr, and J.B. Wilcox, "The Pretest in Survey Research: Issues and Preliminary Findings", Journal of Marketing Research, 1982, pp. 269273.

[39] A. Angleitner, O.P. John, and F.-J. Löhr, "It's What You Ask and How You Ask it: an Itemmetric Analysis of Personality Puestionnaires", in: Personality Assessment via Questionnaires, Springer, 1986, pp. 61-108. 